\title{
A New Channel Reservation and Prediction Concept in Cellular Communication Systems
}

Selma Boumerdassi

Université de Versailles Saint-Quentin, Laboratoire PRiSM 45, avenue des Etats-Unis. 78035 Versailles Cedex France Phone: +33139254076 Fax: +33139254057 Email: Selma.Boumerdassi@prism.uvsq.fr

\begin{abstract}
In future wireless networks, the determination of the amount of resources that a base station (cell) must reserve to maintain a certain call dropping probability is likely to become a very important issue. We present in this paper a new algorithm for channel assignment in wireless networks called Predictive Reservation Policy (PRP) based on FCA concept. This new dynamic channel reservation scheme, adapts the number of guard channels in each cell to: 1) the current number of ongoing calls in neighbouring cells and 2) on the anticipation of the future localisation of users.

The proposed scheme for radio channel allocation reduces handoff call blocking probability substantially at the expense of slight increases in new call blocking probability by giving resource access priority to handoff calls over new calls. PRP improves classical FCA and FCA with 2 or 3 reserved channel for Handoff exclusively.
\end{abstract}

\section{Keywords}

Adaptive bandwidth resource management, prediction, channel reservation, transition probability 


\section{INTRODUCTION}

The bandwidth in a wireless network is perhaps the most precious and scare resource of the entire communication system. This resource should be used in the most efficient manner. A base station sometimes may need to reserve resources, even if this means denying access to a mobile terminal requesting admission to the network, in order to keep enough resources to support active users currently outside of its coverage area, but who may soon emigrate to its cell. Base stations must maintain a balance between the two conflicting requirements: 1) maintaining maximum resource (bandwidth) utilisation and 2) reserving enough bandwidth resources so that the maximum rate of unsuccessful incoming handoffs (due to insufficient resources) is kept below an acceptable level. The probability of unsuccessful handoff can be established in terms of quality-of-service (QoS) metric, e.g. call dropping probability, that the network agrees to maintain [Lev 97].

In this article, we propose a new approach (Predictive Reservation Policy - PRP [Bou 97]) based on FCA [Cho 82]. This scheme is based on the assumption that a mobile does not move randomly. This is due to the existence of roads, highways, dead-ends, shops, etc. On the road, a car is going along in a determined direction. The presence of a park implies that there are only pedestrians.

This paper shows that if some cell to cell handoff probabilities are known even approximately, it is possible to use them in order to manage the bandwidth efficiently. Indeed, if destinations of mobiles are approximately known, it may be interesting to reserve resources which will be freed when the flow will decrease (end of communication for example).

This paper is divided into the following sections. Section 2 describes the new scheme PRP. Simulation results are presented and discussed in Section 3. The conclusion is given in section 4.

\section{DESCRIPTION}

Future personal communication networks (PCN's) will employ microcells and picocells to support higher capacity [Yu 97], thus increasing the frequency of call handoffs, and so the network call processor becomes a bottleneck. A possible solution is the virtual connection tree [Aca 94] [Nag 94], for which the geographical areas are divided into zones named "cell clusters". Each cluster is managed by an ATM switch (see Fig. 1). The treatment of handoff within a cluster is local. This approach decentralises the management and prevents a bottleneck at the network call processor. To implement PRP we can use the virtual tree concept. 


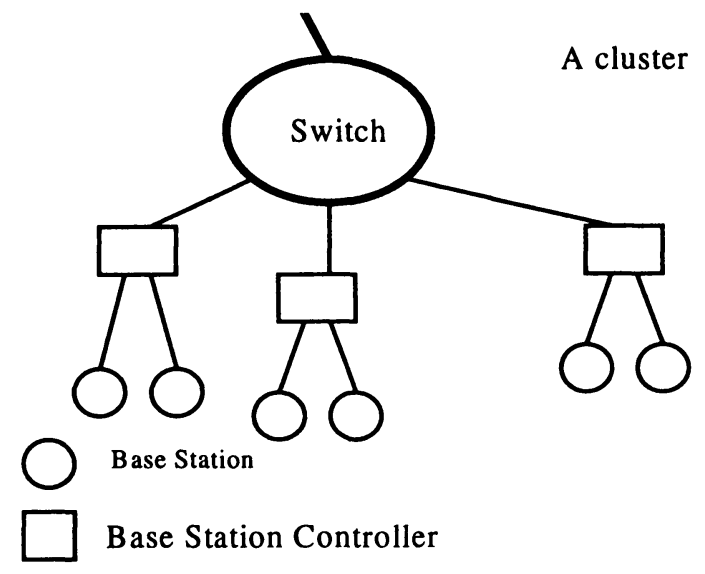

Figure 1 The adaptive architecture for PRP scheme.

PRP dynamically reserves radio resources under certain conditions of traffic, taking into account the actual situation in the covered region (by the base stations). The policy is based on two fundamental and linked elements: reservation and prediction. In this concept, communications in progress have a higher priority than new calls.

\subsection{Reservation scheme}

We consider a wireless network where $i \in I$ denotes a base station (or a cell), and I is the set of the all base stations in the network. $N(i, j)$ denotes the neighbour number $j$ of cell $i\left(j \in[1 . .6]\right.$ in the case of an hexagonal cell). Let $M_{i}(t)$ denote the number of occupied channel in cell $i$ at time $t$.

In a base station, when the number $\mathrm{M}_{\mathrm{i}}(\mathrm{t})$ of occupied channel reaches a threshold $\mathrm{K}$ or a multiple of $\mathrm{K}$ (see Fig. 2), cell $\mathrm{i}$ reserves one channel in all its neighbours $\mathrm{N}(\mathrm{i}, \mathrm{j})$. If $\mathrm{N}(\mathrm{i}, \mathrm{j})$ has an available channel the reservation takes place immediately; else, the reservation has to wait for a free channel. A reserved channel represents a potential arrival of communication. In this case the cell considers that the channel is occupied by a virtual (or a potential) mobile. 


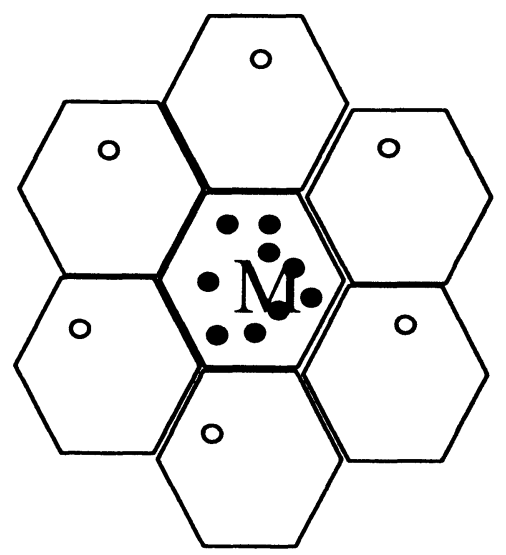

Example $: K=10$

$M_{\mathrm{i}}(\mathrm{t})=10=>$

$1^{\text {st }}$ reservation (or ask for reservation) in the neighbours of $i$.

$M_{i}(t)=20=>$

$2^{\text {nd }}$ reservation (or ask for reservation) in the neighbours of $i$.

Also, the reservation is cancelled when the number of occupied channels leaves threshold.

Example : $K=10$

When $M_{i}(t)$ gets down from 20 to $19=>$ the $2^{\text {nd }}$ reservation (or ask of reservation) is cancelled.

Figure 2 Principle of reservation.

The channels which are blocked as mentioned in Fig. 2 are reserved for handoffs. It is important to notice that a channel is not only reserved for the cell which reserves; it can also be used by the handoffs from all the neighbouring cells (e.g., a handoff can come from any neighbour). In case of overload (or a state close to overload), the system does not accept incoming calls, it only processes calls in progress.

\subsection{Prediction}

In a wireless network, call arrival, call departure, and call handoff rates depend on the presence of roads, houses, and other topological features, ... Thus, mobiles do not randomly move: most of the time their trajectories are foreseeable. For example, cars run along roads and are not usually present in dead-ends. In such a context, it would be very interesting to reserve resources to optimise the global performance of the system (i.e. call in progress should have a higher access priority to resources). In the PRP approach, each cell of the system are associated probabilities of transition to its neighbours. Measurements could be performed in order to estimate these probabilities. The reservation threshold must take into account the traffic characteristics. 


\subsection{Algorithms}

PRP can be resumed by the followings algorithms :

\section{Reservation (Uniform traffic case)}

If a multiple of the threshold is reached

Then A reservation is set in each neighbouring cell

\section{Reservation (Non uniform traffic case)}

For each neighbour $\mathrm{j}$

If a multiple of the threshold is reached

Then A reservation is set in neighbour $N(i, j) i$

\section{Getting in cell}

If the number of free channels $>0$

Then The communication is established

Reservation

Else If New Call

Then The communication is blocked

Else If the number of reserved channels $>0$

Then The communication is established Reservation

Else The Hand Off is dropping

\section{Unreservation (Uniform traffic case)}

If a multiple of the threshold is lost

Then A reservation is cancelled in every neighbouring cell

\section{Unreservation (Non uniform traffic case)}

For every neighbour $\mathrm{j}$

If a multiple of the threshold is lost

Then A reservation is cancelled in neighbour $N(i, j)$

\section{Getting out cell}

Unreservation

End of the communication 


\section{SIMULATION AND ANALYSIS}

Two cases were studied:.

\subsection{Uniform case}

The local topology is not taken into account. It is considered that mobiles enter all the neighbour cells with the same probability (see Fig. 3). In this case, when a threshold is reached in a given cell the base station asks for reservation in all the surrounding cells.

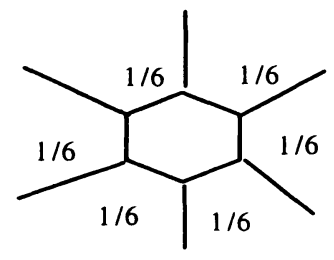

Figure 3 Probability for the uniform case.

\subsection{Non uniform case:}

In this more realistic case, the transition probabilities depend on the local topology (Fig. 4).Thus, the reservation threshold varies inversely with the probability of visit to the neighbouring cells. The interval $[0,1]$ is divided into three intervals: at each one a reservation threshold $\left(\mathrm{K}_{0}, \mathrm{~K}_{1}, \mathrm{~K}_{2}\right)$ is associated to each one of them.

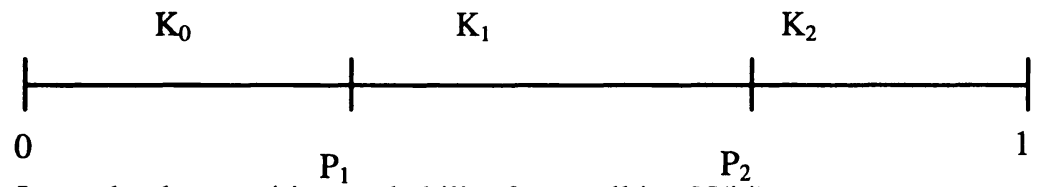

Let $p_{i j}$ be the transition probability from cell $i$ to $N(i, j)$ :

If $0 \leq \mathrm{p}_{\mathrm{ij}}<\mathrm{P}_{1}$ cell $\mathrm{i}$ reserves in cell $\mathrm{j}$ with the threshold $\mathrm{K}_{0}$;

If $\mathrm{P}_{1} \leq \mathrm{p}_{\mathrm{ij}}<\mathrm{P}_{2}$ cell $\mathrm{i}$ reserves in cell $\mathrm{j}$ with the threshold $\mathrm{K}_{1}$;

If $p_{i j} \geq P_{2}$ cell $i$ reserves in cell $j$ with a threshold of $K_{2}$. 


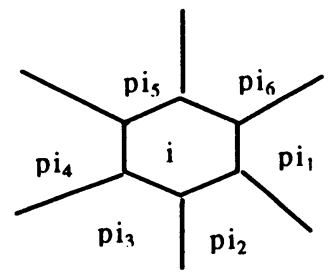

$\mathrm{p}_{\mathrm{ij}}$ : probability to go from $\mathrm{i}$ to $N(i, j)$.

$$
\sum_{j=1}^{6} \mathrm{p}_{\mathrm{ij}}=1
$$

Figure 4 Probability for the non uniform case.

\subsection{Simulation model}

To simulate the system a cell cluster with 30 hexagonal has been considered. As shown in Fig. 5 edge effects on handoffs at the cluster boundary are handed by wrapping them around thereby assuming that arrival rates and handoff departure rates from cluster to cluster are equivalent. The call duration is exponentially distributed with a mean value of 120 seconds and the time a mobile spends in a cell is also assumed to be exponentially distributed with a mean value of 50 seconds. In our model, the new calls arrival distribution is assumed to be Poisson with parameter $\lambda_{i}$. (for cell $i$ ). To obtain a non uniform traffic on the cell cluster different values of the parameters $\lambda_{i}$ were chosen. Let $\lambda$ be the global cell cluster rate we choose:

$\lambda=\sum \lambda_{\mathrm{i}}$

$$
\text { with } \lambda_{\mathrm{i}}=\lambda_{\mathrm{j}} \quad \Rightarrow \quad \mathrm{i}=\mathrm{j}
$$

- Each base station manages $C=24$ channels

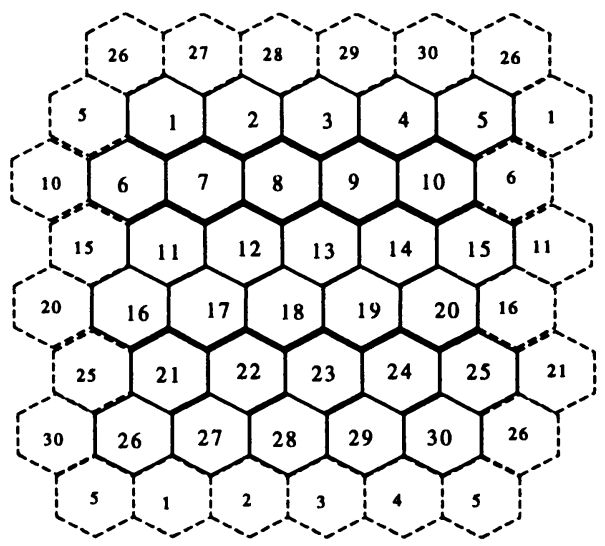

Figure 5 Cluster of 30 cells. 


\subsection{Results and analysis}

In each simulation run, we generate about 2 million calls for the cluster. The result (grade of service and blocking probabilities) concerns all the clusters. The relative confidence intervals for the blocking probabilities were calculated, they are around $10 \%$. The simulation has been written in QNAP2.

The grade of service used is :

$G o S=10^{*}$ Hand off failure probability + New call block probability.

\subsubsection{Results: uniform case}

Several thresholds where tested and Figure 6 shows that the lower the reservation threshold the lower the hand off failure probability. Moreover, when the load is low enough, the reservation has no effect on performance. Inversely, with a reservation under a high load, the number of handoff droppings decreases significantly. Figure 7 shows the influence of reservation on new call blocks: the more reservations are supported, the larger the number of refused incoming calls. Table 1 represents the Grade of Service for different thresholds as a function of the traffic load (Erlangs). PRP results are compared with classical FCA, and this leads to good performance from threshold 14. The best results are obtained with threshold 16 (see Fig. 8, 9 and 10). When the input load is quite low, the reservation algorithm has no effect on the Grade of Service, because few cells are overloaded. When the input load increases, the thresholds are often reached and reservation are consequently efficient.

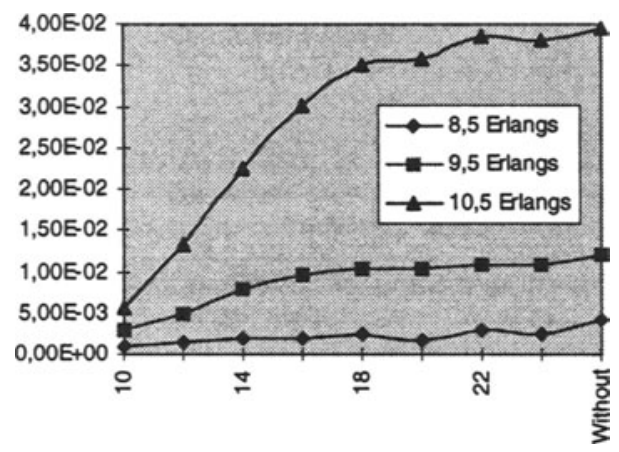

Figure 6 Handoff failure probability for different thresholds.

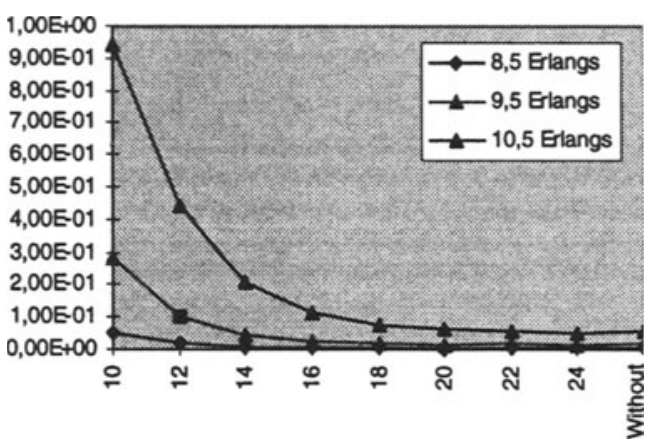

Figure 7 New call block probability for different thresholds. 


\begin{tabular}{llll|l|lllll}
\hline & & & & & \multicolumn{3}{|l}{ Threshold } & & \\
\hline Erlangs & 10 & 12 & 14 & 16 & 18 & 20 & 22 & 24 & Without \\
\hline 7,5 & $7,87 \mathrm{E}-03$ & $3,14 \mathrm{E}-03$ & $4,06 \mathrm{E}-03$ & $5,41 \mathrm{E}-03$ & $5,15 \mathrm{E}-03$ & $5,28 \mathrm{E}-03$ & $5,52 \mathrm{E}-03$ & $6,02 \mathrm{E}-03$ & $4,28 \mathrm{E}-03$ \\
8,5 & $6,07 \mathrm{E}-02$ & $3,13 \mathrm{E}-02$ & $2,71 \mathrm{E}-02$ & $2,41 \mathrm{E}-02$ & $2,97 \mathrm{E}-02$ & $2,04 \mathrm{E}-02$ & $3,43 \mathrm{E}-02$ & $2,94 \mathrm{E}-02$ & $4,49 \mathrm{E}-02$ \\
9,5 & $3,14 \mathrm{E}-01$ & $1,49 \mathrm{E}-01$ & $1,23 \mathrm{E}-01$ & $1,22 \mathrm{E}-01$ & $1,26 \mathrm{E}-01$ & $1,18 \mathrm{E}-01$ & $1,27 \mathrm{E}-01$ & $1,25 \mathrm{E}-01$ & $1,39 \mathrm{E}-01$ \\
10,5 & $9,99 \mathrm{E}-01$ & $5,76 \mathrm{E}-01$ & $4,31 \mathrm{E}-01$ & $4,17 \mathrm{E}-01$ & $4,25 \mathrm{E}-01$ & $4,18 \mathrm{E}-01$ & $4,41 \mathrm{E}-01$ & $4,32 \mathrm{E}-01$ & $4,51 \mathrm{E}-01$ \\
11,5 & $2,44 \mathrm{E}+0$ & $1,56 \mathrm{E}+0$ & $1,16 \mathrm{E}+0$ & $1,08 \mathrm{E}+0$ & $1,11 \mathrm{E}+0$ & $1,18 \mathrm{E}+0$ & $1,18 \mathrm{E}+0$ & $1,19 \mathrm{E}+0$ & $1,22 \mathrm{E}+0$ \\
\hline
\end{tabular}

Table 1 Grade of Service in a uniform traffic case.

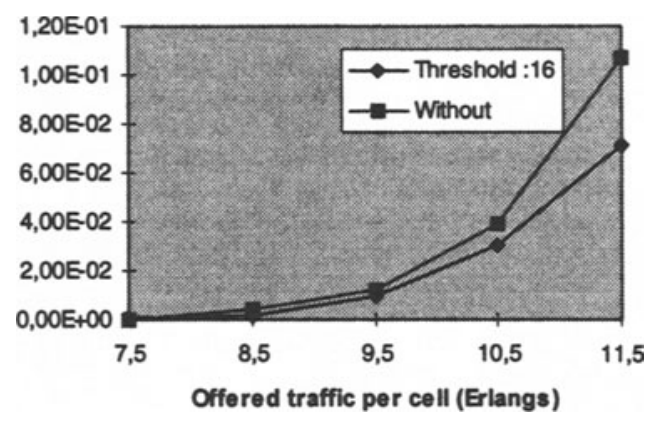

Figure 8 Handoff failure probability with a threshold of 16

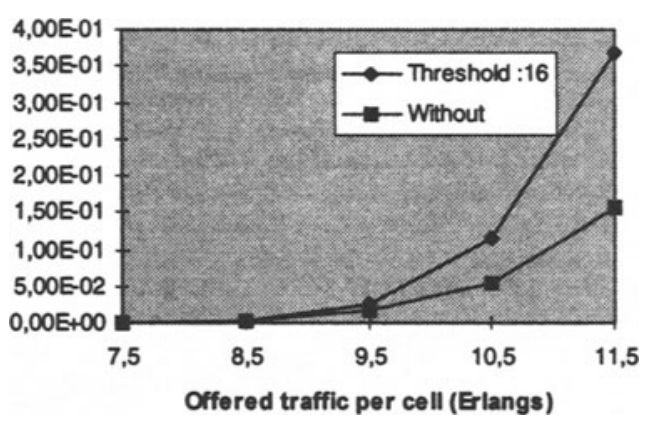

Figure 9 New call block probability with a threshold of 16 


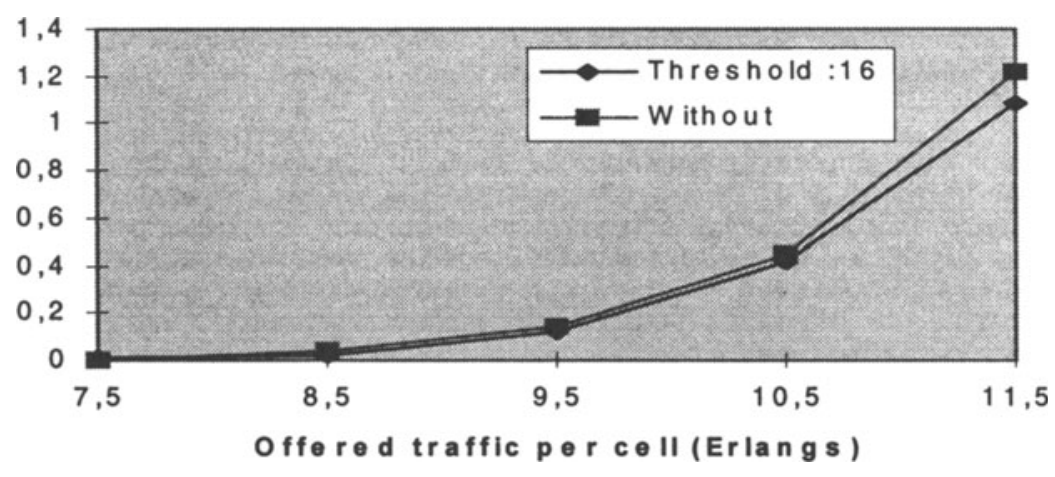

Figure 10 Grade of Service with a threshold of 16

\subsubsection{Results: non uniform case}

Figure 11 represents the Grade of Service as a function of the traffic load (expressed in Erlangs). PRP reservation results are compared to those obtained using FCA (which corresponds to the case where there is no reservation for handoff traffic). PRP reservation and prediction can improve significantly traditional FCA. Figure 12 and 13 show the influence of PRP on HandOff probability and New Call probability. PRP has to be tested with real data.

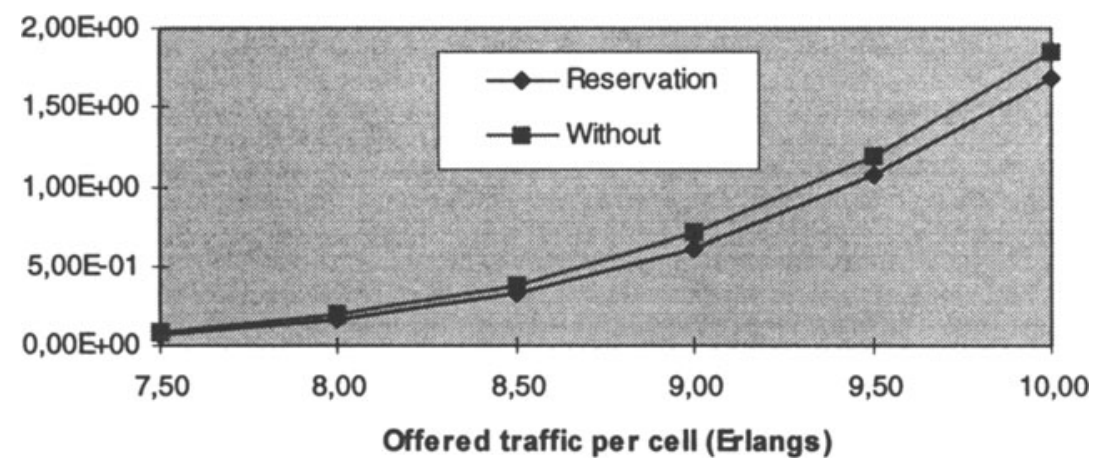

$\mathrm{K}_{0}=25, \mathrm{~K}_{1}=14, \mathrm{~K}_{2}=10$ and $\mathrm{P}_{1}=0.35, \mathrm{P}_{2}=0,5$

Figure 11 Grade of Service in non uniform case 


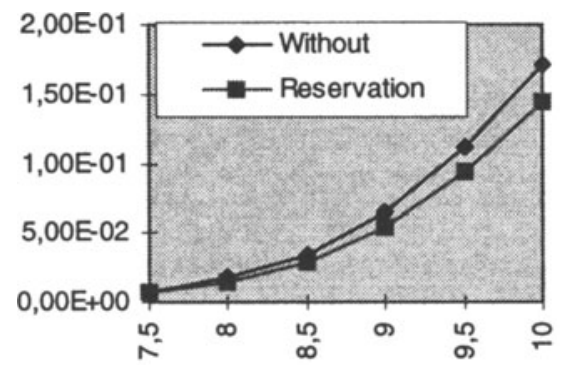

Offered traffic per cell (Erlangs)

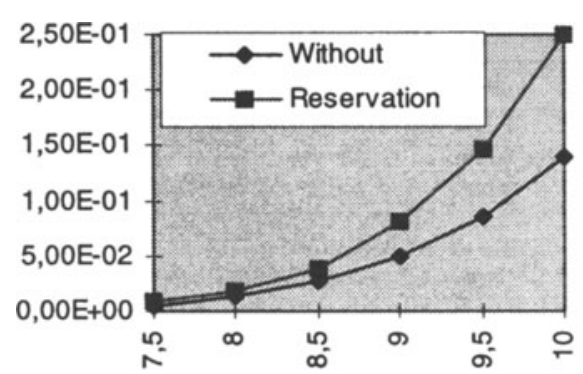

Offered traffic per cell (Erlangs)

Figure 12 Handoff failure probability

Figure 13 New call block probability

\subsection{Comparison between PRP and FCA with fixed reservation}

Figures 14 and 15 represent the Grade of Service as a function of the traffic load (expressed in Erlangs). PRP results are compared to those obtained using a fix number of reservation ( 2 and 3 in each cell) for HandOff traffic. It is shown that PRP leads better performance results. This is due to the fact that PRP reservations are adapted to the traffic and to the local topology. We obtain the same results with uniform case (with a threshold of 16) and non uniform case.

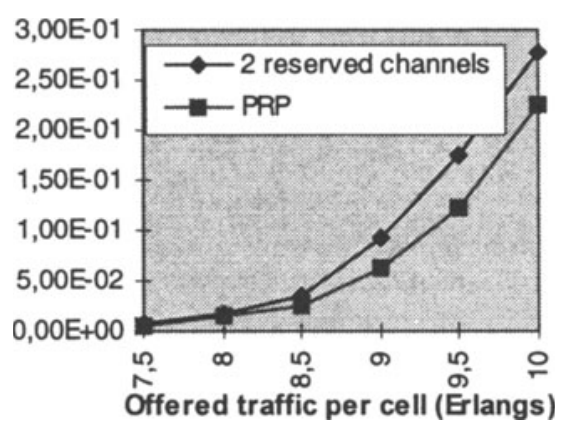

Figure 14 Grade of Service

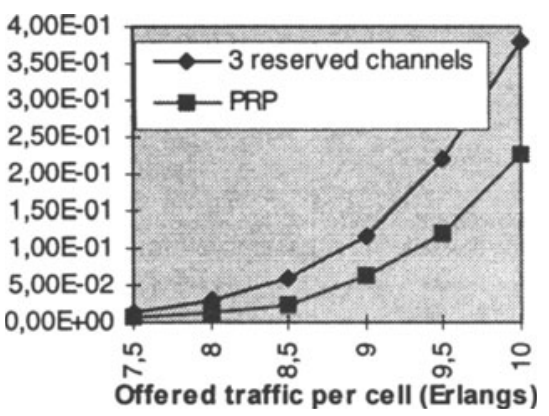

Figure 15 Grade of Service 


\section{CONCLUSION}

PRP concept is likely to be very useful in any wireless network with small cells, irregular topology and time-varying traffic load (hot spot for example). We showed in this article the applicability and usefulness of PRP mechanism with simulation experiments. We have shown that with this new approach the bandwidth is better used if we take into account the characteristics of the traffic and the local topology. Indeed, with these simulations, a load corresponds to a threshold and a threshold corresponds to a probability of visit. If real data on the traffic characteristics become available we could find optimal values that result in PRP that is practical and manageable.

For future researches, we are thinking to make base stations "more intelligent" to calculate the thresholds automatically using the characteristics of the environment. Indeed, it is possible to find a daily (or weekly) regularity on the conditions of traffic, and - in the same way - a regularity on the movement of mobiles.

\section{REFERENCES}

[Aca 94] A.S. Acampora and M. Naghshineh - An Architecture and Methodology for Mobile-Executed Handoff in Cellular ATM Networks - IEEE Journal On Selected Areas In Communications, VOL. 12, NO.8, October 1994.

[Bou 97] S Boumerdassi, A New Concept to Optimize Channel Management in Cellular Communication Systems, MWCN'97, Paris, May 97.

[Cho 82] G.L. Choudury, S.S. Rappaport - Cellular Communication Schemes Using Generalized Fixed Channel Assignment and Collision Type Request Channels - IEEE Transactions on Vehicular Technology, Vol VT-31, pp. 53-65, May 1982.

[Lev 97] David A. Levine, Ian F. Akyildiz and Mahmoud Naghshineh - A Resource Estimation and Call Admission Algorithm for Wireless Multimedia Networks Using the Shadow Cluster Concept - IEEE/ACM Transactions on Networking, Vol 5, NO 1, February 97

[Nag 94] A.S. Acampora and M. Naghshineh - Distributed call admission control in mobile/wireless networks - IEEE Personal Communications, Second Quarter 1994.

[Ray 92] D. Raychoudhuri, A.D. Wilson - Control and Quality-of-Service Provisioning in High-Speed Microcellular Networks - IEEE Journal on Selected Areas in Communications, Vol SAC-12, nº , October 1992.

[Yu 97] O.T.W Yu and V.C.M Leung - Adaptative Resource Allocation for Priotized Call Admission over an ATM-Based Wireless PCN - IEEE Journal on Selected Areas in Communications, Vol SAC-15, n 7 , pp 1208-1225, September 1997. 